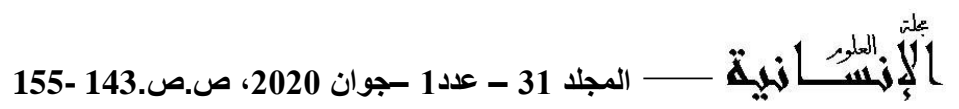

\title{
ماهية الترجمة ودورها في إثراء الهوية الثقافية
}

\author{
Definition and Role of Translation In Enriching Cultural Identity \\ تاريخ الاستلام : 2019/10/21 ؛ تاريخ القبول : 2020/04/04
}

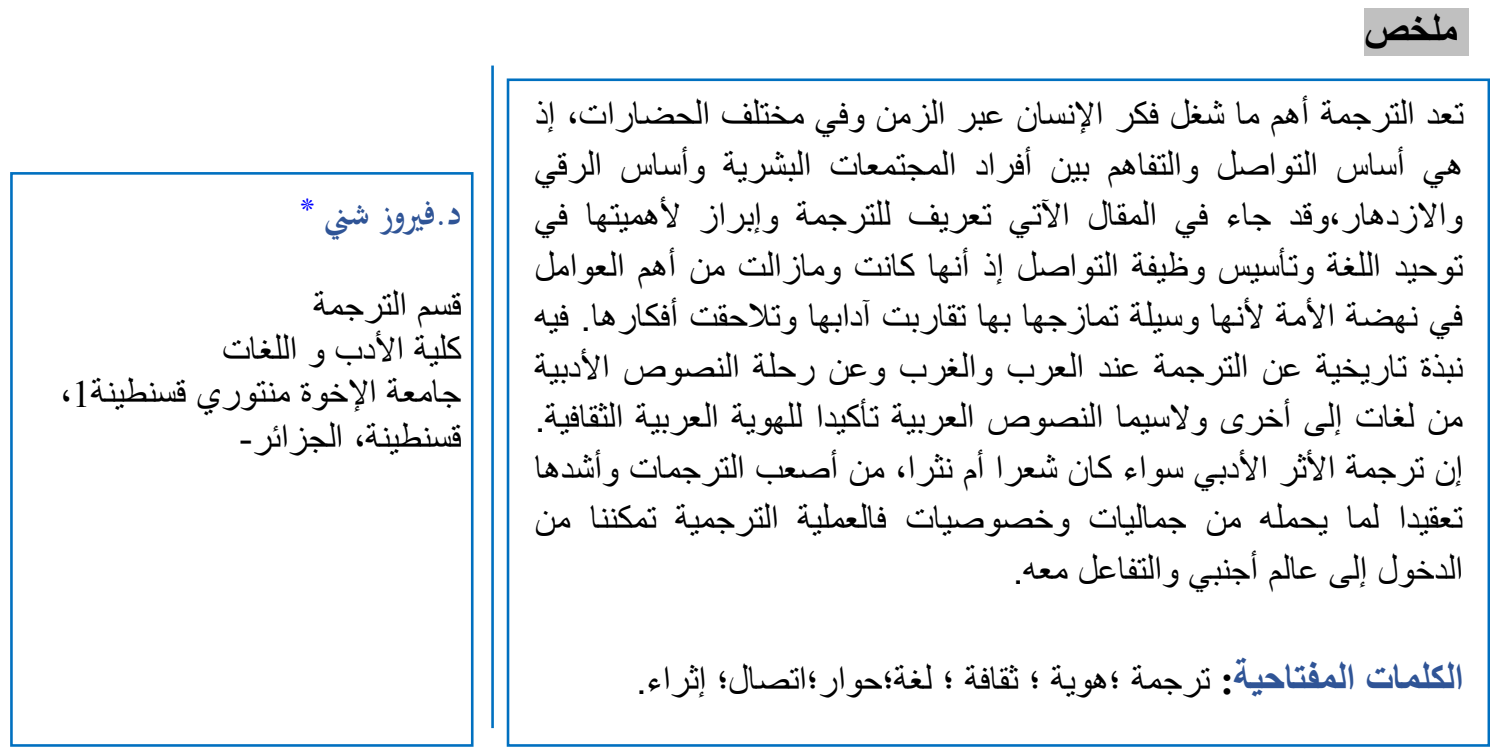

\section{Abstract}

Through time and different civilizations, translation has been one of the most important concerns of man. This is in fact what enables the members of human societies to communicate and is the basis of all development. This article includes a definition of translation and its importance in the unification of the language and its role in the establishment of the communicative function. It has always been an important factor in the rebirth of the nation because it allows it to remain homogeneous, through it that literatures come closer. There is also a historical overview of the translation between the Arab world and the West and the passage of literary texts from one language to another, in this case Arabic texts confirming Arab cultural identity. The translation of the literary effect whether related to poetry or prose, is among the most difficult translations for what it implies as aesthetic traits and specificities. The translation operation allows us to access another universe.

Keywords: Translation; Identity; Culture; Language; Communication; Enriching.

\section{Résumé}

A travers le temps et les différentes civilisations, la traduction a été l'une des plus importantes préoccupations de l'homme. C'est en effet ce qui permet aux membres des sociétés humaines de communiquer et c'est la base de tout développement cet article comprend une définition de la traduction, et son importance dans l'unification de la langue et son rôle dans l'établissement de la fonction communicative. Elle a toujours constitué un facteur important dans la renaissance de la nation car c'est elle qui lui permet de rester homogène, a travers elle que les littératures se rapprochent. On y trouve aussi un aperçu historique sur la traduction entre le monde arabe et l'occident et le passage des textes littéraires d'une langue à une autre, en l'occurrence, les textes arabes confirmant l'identité culturelle arabe. La traduction de l'effet littéraire, qu'il soit relatif à la poésie ou à la prose, fait partie des traductions les plus difficiles pour ce qu'il implique comme traits esthétiques et spécificités. L'opération traductive nous permet d'accéder à un autre univers. Mots clés: Traduction ; Identité ; Culture ; Langue ;Dialogue ;Communication ; Enrichissement.

* Corresponding author, e-mail: fairouzchennie@gmail.com 
الترجمة ضرورة من ضرورات الحياة المعرفية، إنها وسيلة تواصل لا غنى لنا عنها، جو هر كل علم لأن العلم مشاع بين البشر، يتناقله جيل عن جيل، ويتسلم مشعله

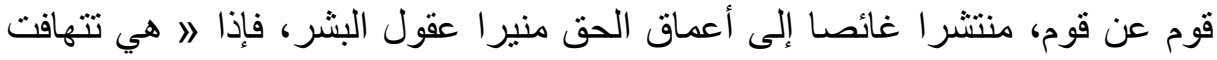
عليه تهافت الفراشة على المصباح و على الحلبة تتو الى الأمم، ساعية، متقدمة أثنواطا

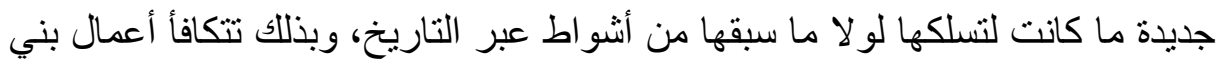
البشر ولئن كان للسابق فضل الابتداء فللاحق فضل الاقتداء ومواصلة السير ومتابعة البناء «(1). وبذللك تبرز أهمية النقل و الترجمة، فما تمثل العقل من مفاهيم وما اتضح

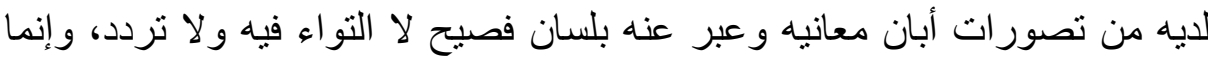

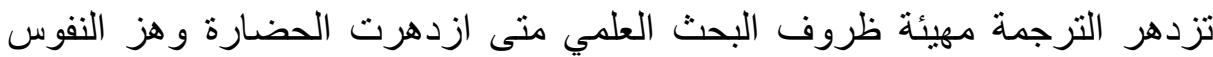

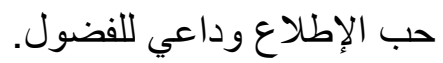

تعريف الترجمة

الترجمة في التعريف اللغوي، وفق ما ورد في المعجم، جاءت من كلمة "ترجم" بمعنى فسر كلام آخر فهو ترجمان وجمعه تراجمة وتراجم ويقال :"ترجمه بالعربية"

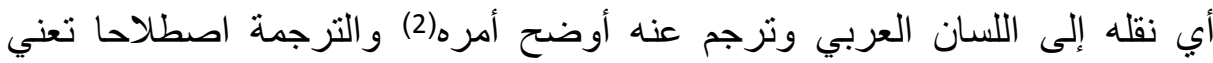
التفسير أو التعبير عن المعنى بلغة أو بإثارات أو برموز أو بحركات أخرى، ويتفق

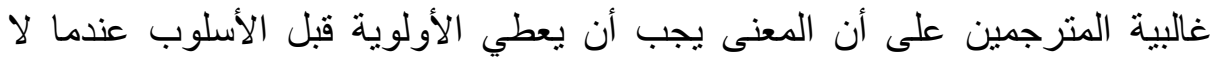

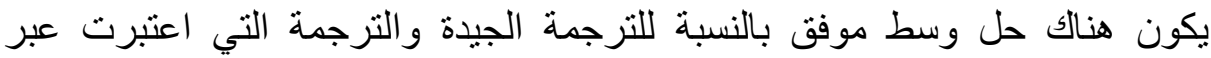

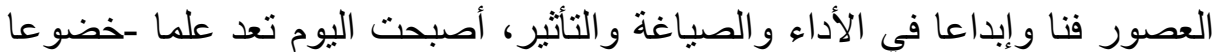

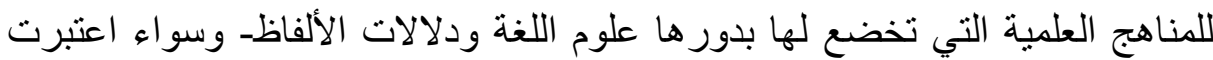
الترجمة فنا أو علما أو كلاهما معا، فهي تبدو قديمة قدم الإنسان على وجه المعدورة،

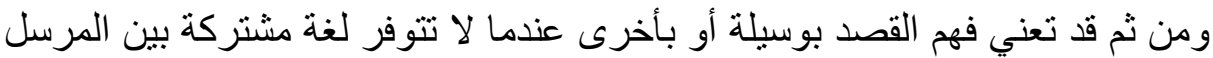

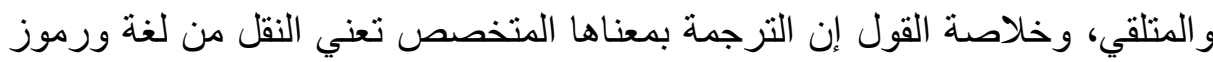
أخرى، بأقصى قدر من الأمانة إلى لغة متلقية، وهذا عمل يتطلب قدرة وسعة إطلاع

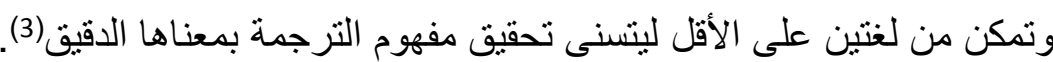

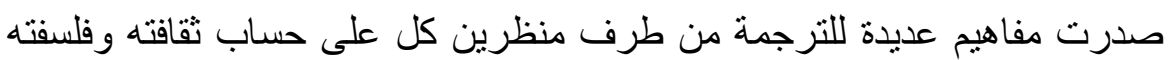
والمذهب الذي ينتمي إليه وأثنهر ما ورد في ذائلك من نعريف منظري الاتجاهين "المصدري" (Courant sourcier) و "الاستهدافي" (Courant cibliste). إن المنظر الفرنسي "أنظوان برمان"(4) (Antoine Berman) ذو الاتجاه المصدري من أشهر المنظرين في عالم الترجمة ويُعرف الترجمة على أنها لا ترجمة الحرف وترجمة النص على أنه حرفي(5). ومن خلال مذهبه وتعريفه فالهدف هو

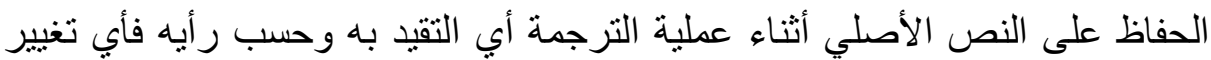

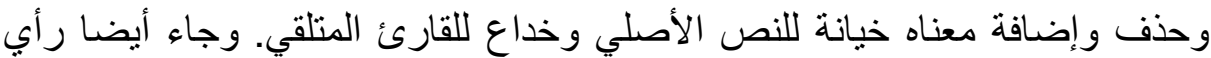
"والتز بنيمين"(6) (Walter Benjamin) مساندا له إذ يعرف الترجمة / بأنها شكلا

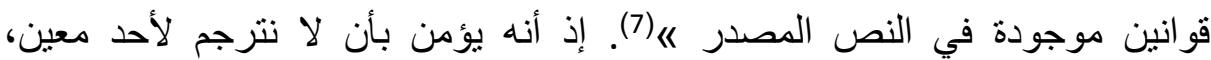
و النص يبدأ برفض المتلقي أي نترجمه دون تصور فورد مسبق لمتلق ما. 
فحسب رأيه \ العمل الأدبي لا يوجه إلى إنسان أو جمهور و إنما يوجه إلى جوهر

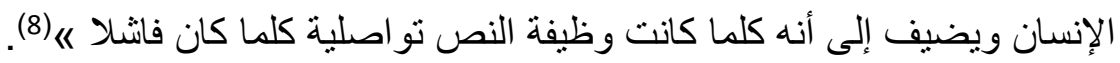

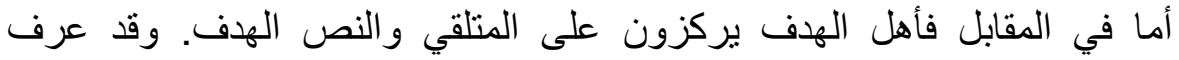
الترجمة "بيل روجر"(9) (Bill Roger) على أنها / التعبير بلغة أخرى (لغة الغة الهدف)

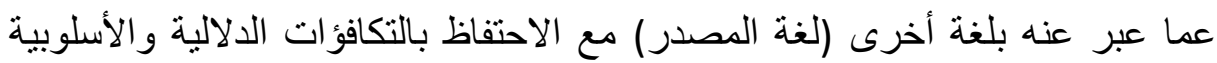

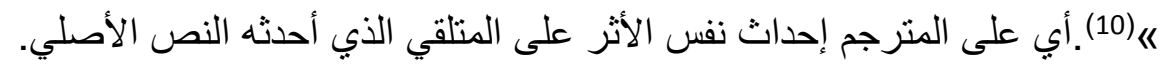

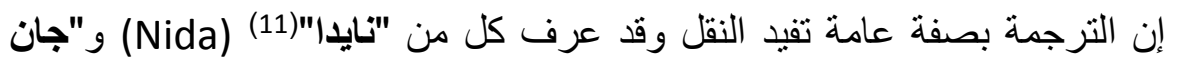

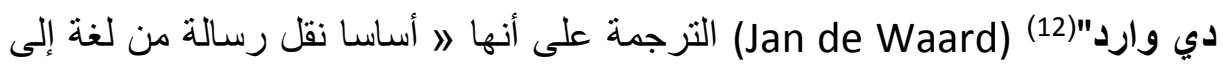

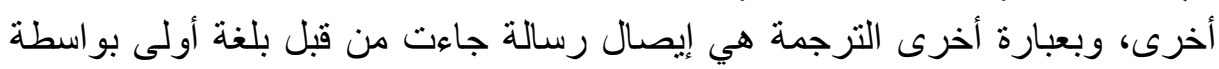

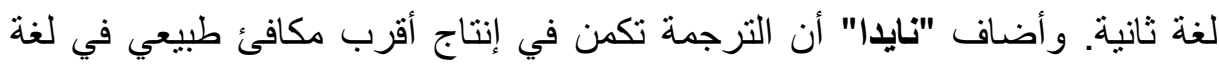

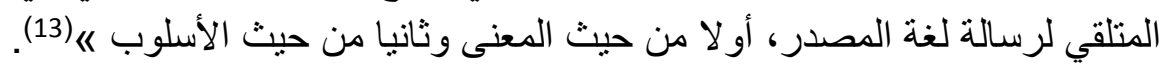
وظائف الترجمة لرنة

إن للترجمة عدة وظائف منها الوظيفة الثقافية والحضارية واللغوية، فقد أسهمت

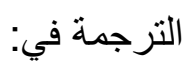

1- الكشف عن إنتاج أدبي مغمور سبق زمانه:

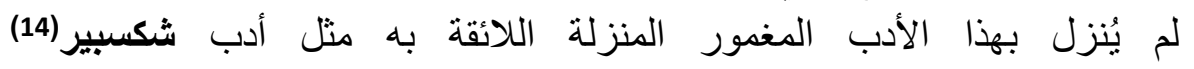
(Shakespeare)

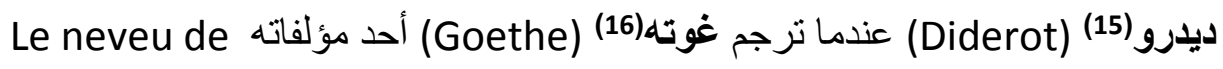
Rameau

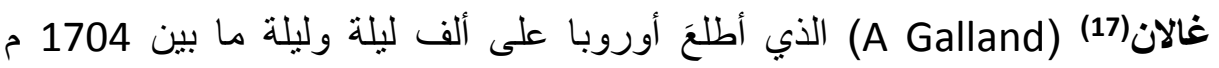

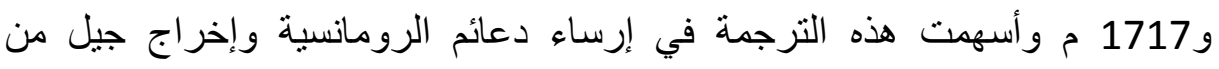
العباقرة في الأدب. 2-

تساعد الترجمة على توحيد اللغة كما حدث بالنسبة للغة الفرنسية مع دي بلي (18) (Du Bellay)

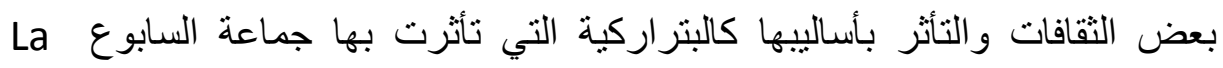

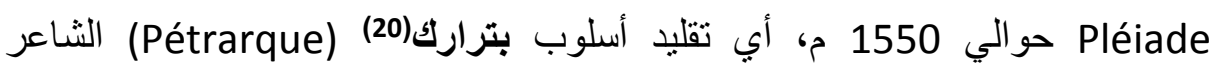
الايطالي ويكفي أن الأمم التي اهتمت بالترجمة هي دوما لتما في الطليعة، ذلك لأنها

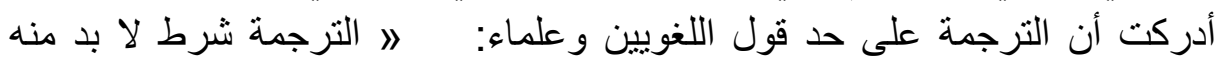
(21) «

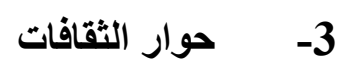

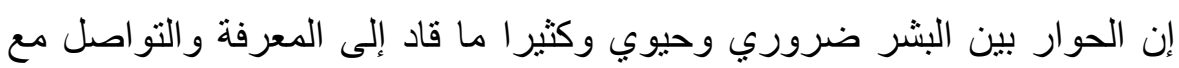

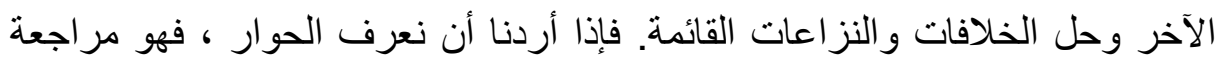

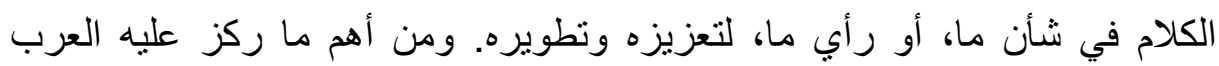

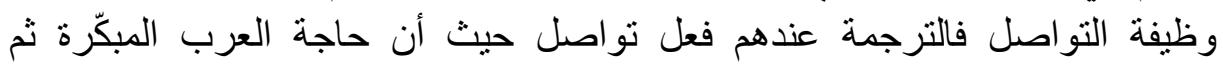

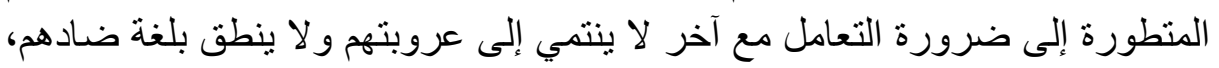

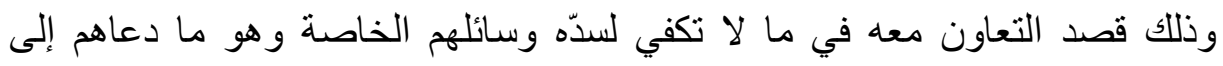

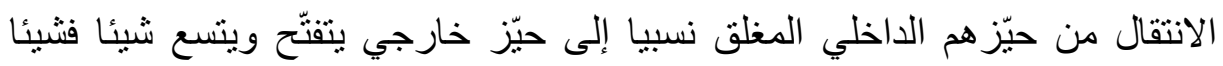




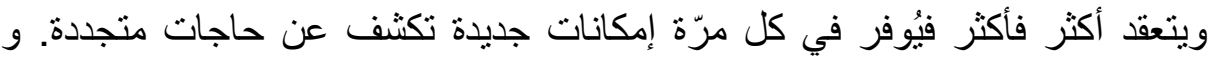

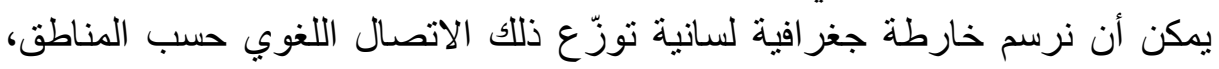

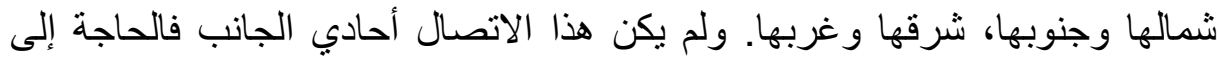

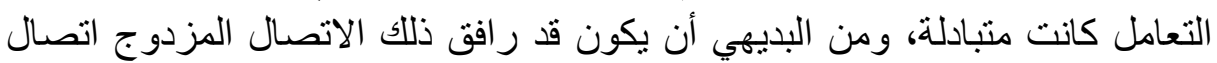

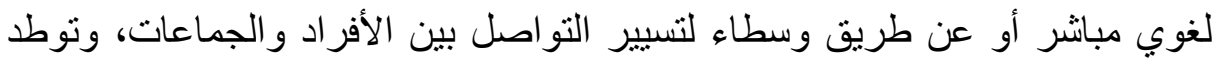

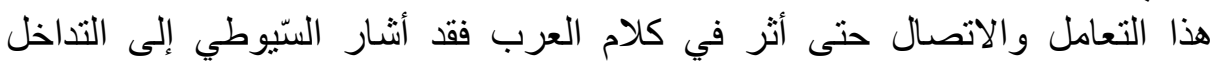

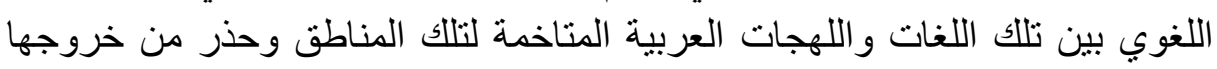
عن الصّفوية العربية(22). ومع مرور الوقت وتطور الأحداث اتسعت العلاقات وتعمّق

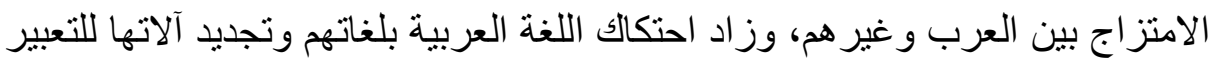

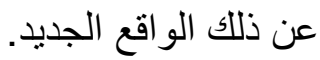

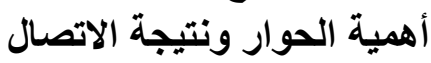

هذا الاتصال بالعناصر الأجنبية قد أكسب اللغة العربية رحابة وقوة بحيث ظهرت

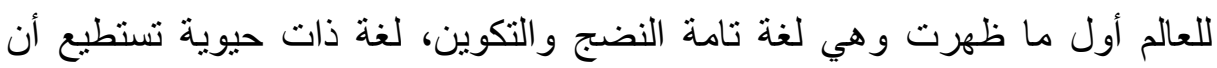

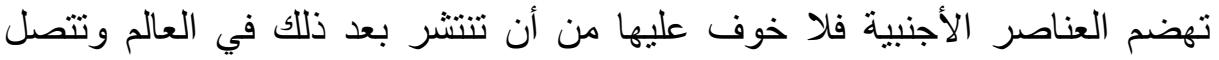

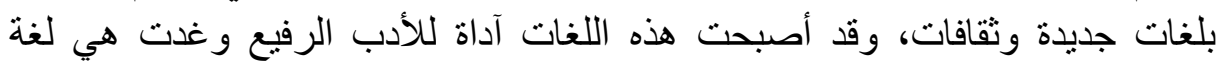

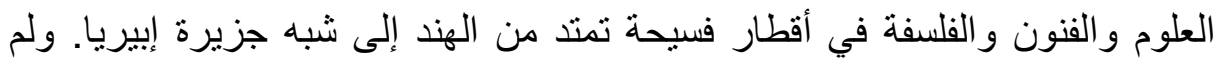

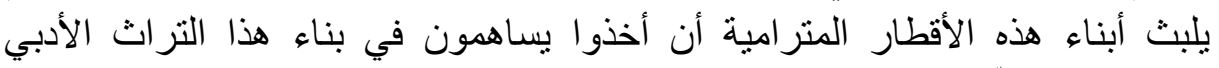

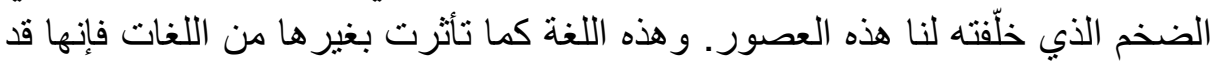

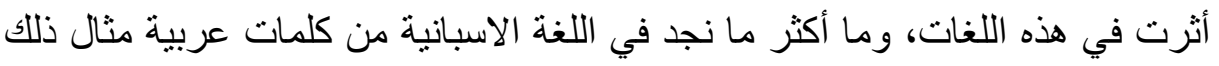

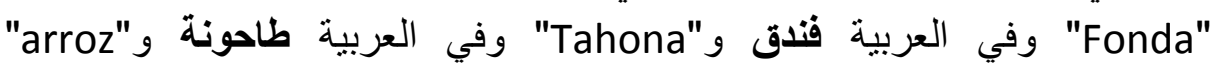

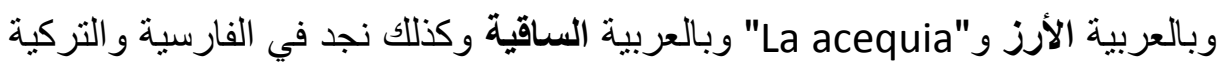
جملة كبيرة من الكلمات العربية بل لقد دخلت عدة كلمات عربية في اللغات الأجنبية

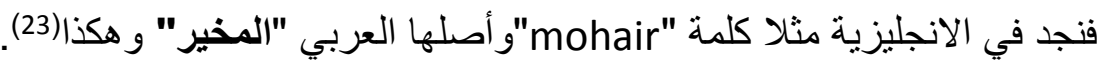

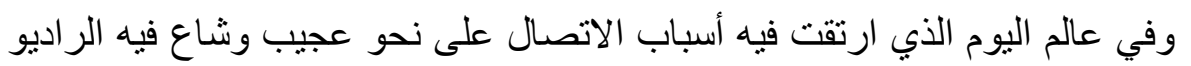

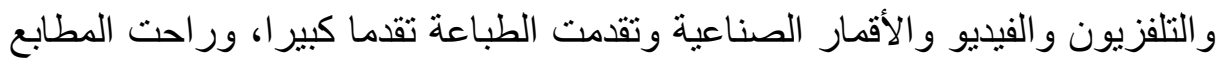

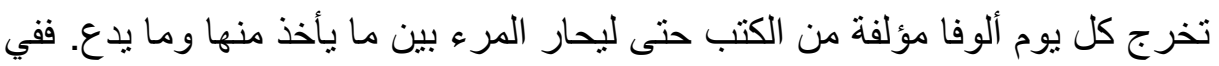

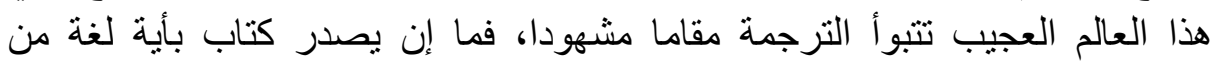

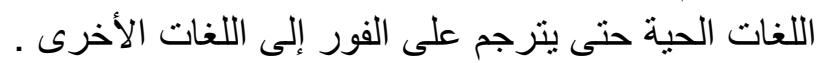

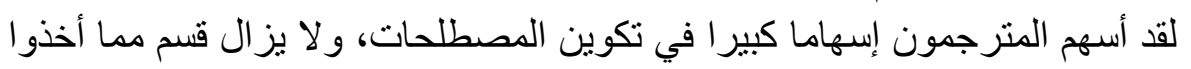
به مستعملا إلى اليوم. وقد عوّلوا على العربية أولا في وضع الكان مصطلحاتهم فاستعاروا

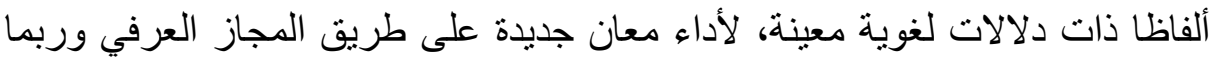

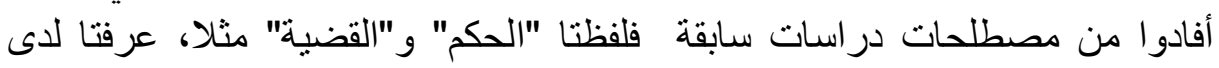
الفقهاء قبل أن تعرف لدى الفلاسفة والمناطقة، و إذا لم يجدوا في العربية اللفظ الملائم

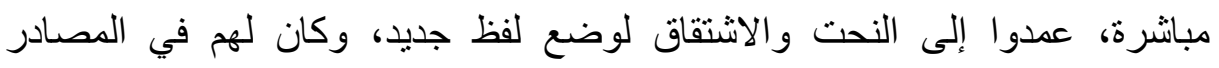

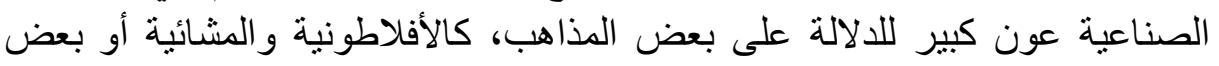

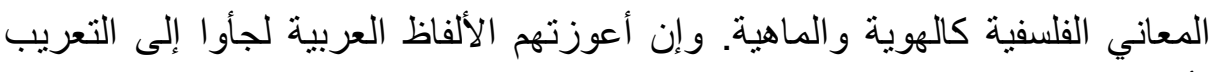

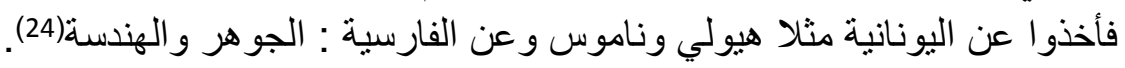




\section{أ- الترجمة عند العرب}

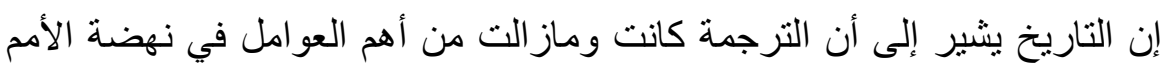

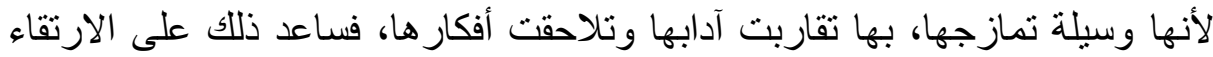

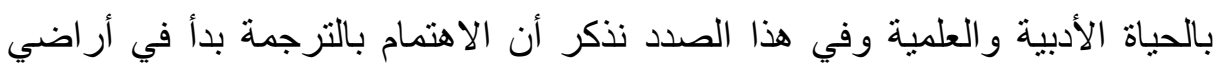

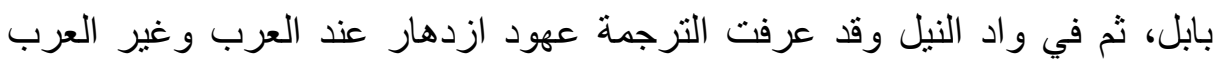

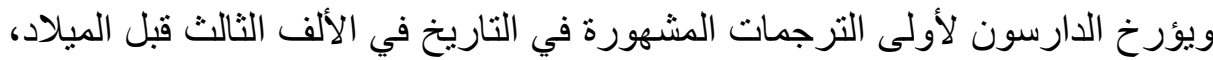

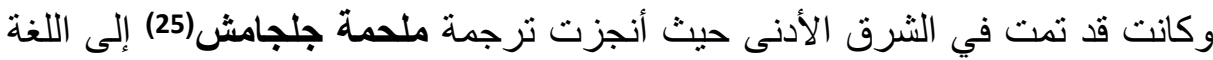
الحثية(26) عن اللغة السومرية.

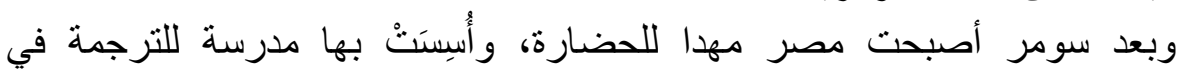

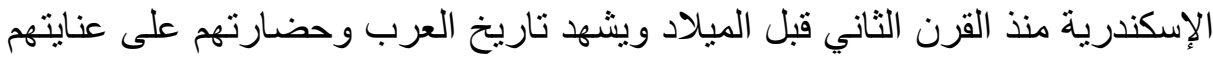

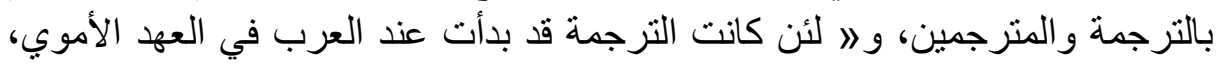
فإن العصر العباسي تميز بها حتى بلغت أوجها في عهد الخليفة المأمون(27) (813-

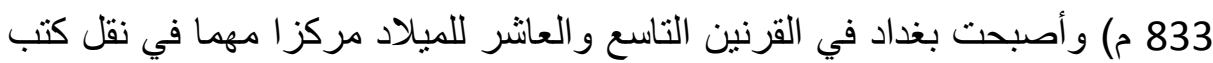

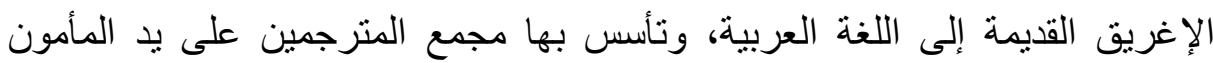
(28) « تأتي الترجمة بدافع الحاجة و هذه الأخيرة تأتي قبل مرحلة اللذة والاستمتاع العقلي

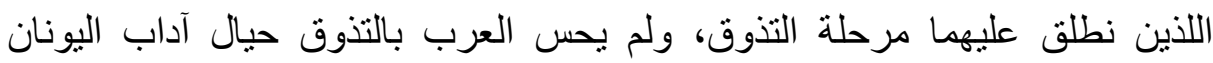
و أساطير هم ومسرحياتهم فلم يترجموا منها شيئا. و التذوق يختلف في الأمة الواحدة تبعا

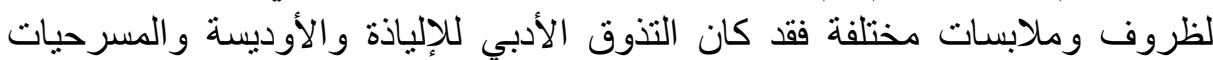

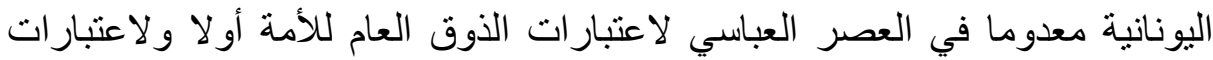

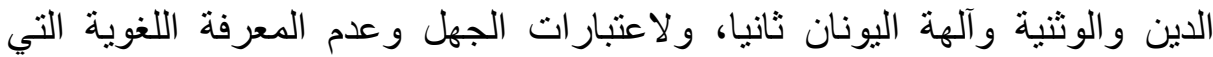

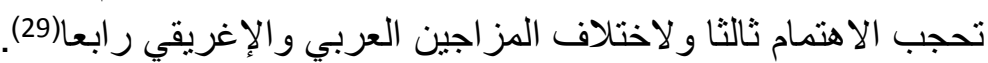

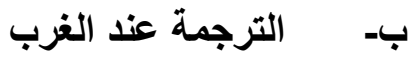

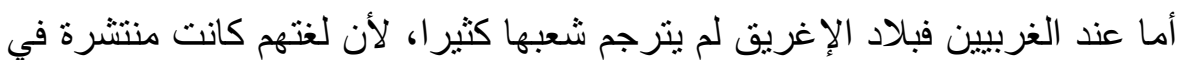

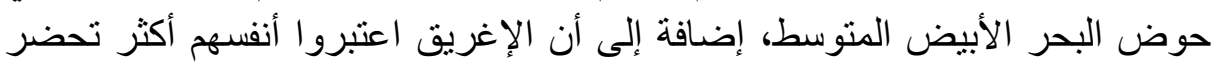

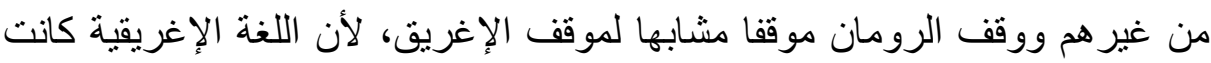

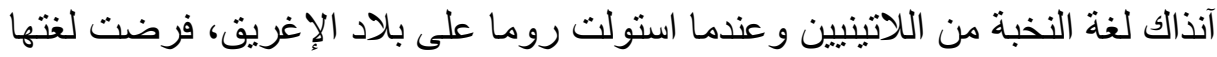

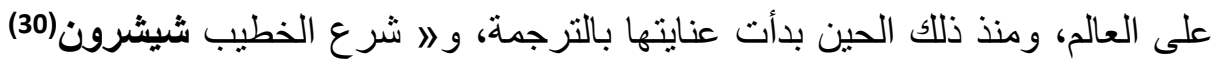

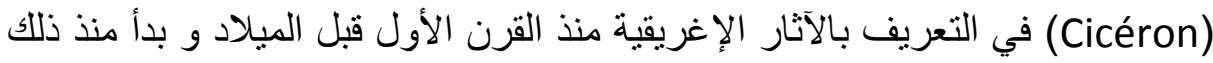
الحين يهتم بالأسس النظرية للترجمة هاب(31).

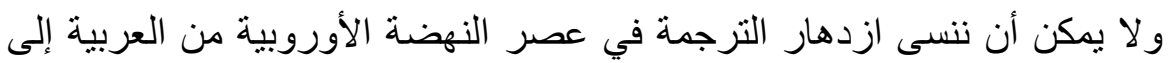

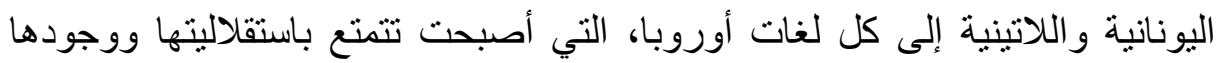

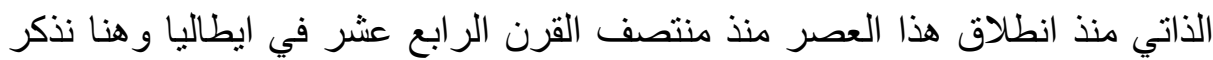
بدور مدرسة طليطلة (Tolède) في الأندلس التي أصبحت مركزا مرموقا لترجمة

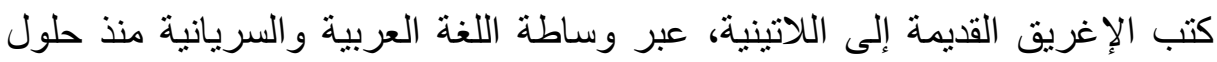

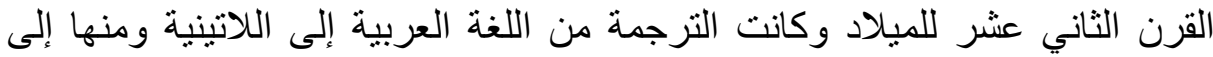
اللغات الأخرى، لها أثرها العظيم الذي استمر أكثر من أربعة قرون من خلال كتب التب التب 


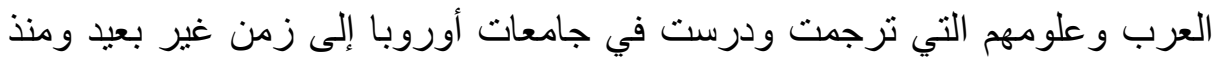

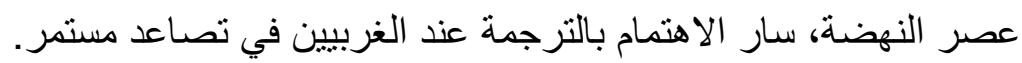

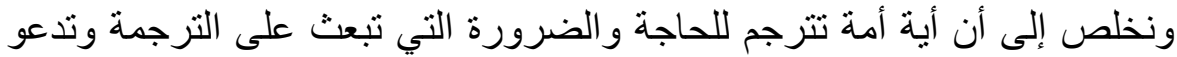

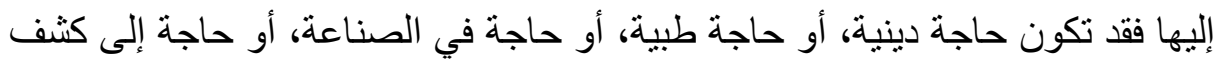

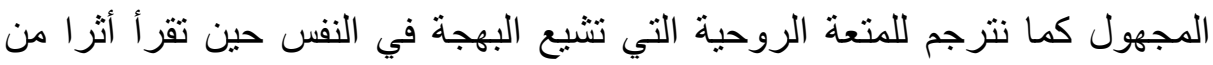

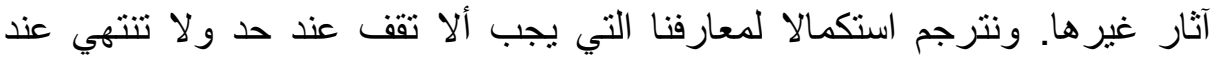
غاية، ونترجم تعزيز المقومات شخصياتنا التي تزيدها القر اءة قوة واستقلالا ونترجم

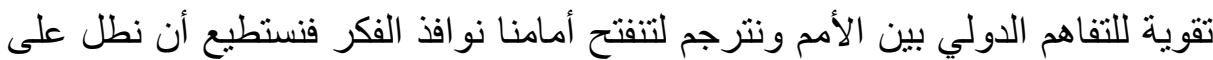

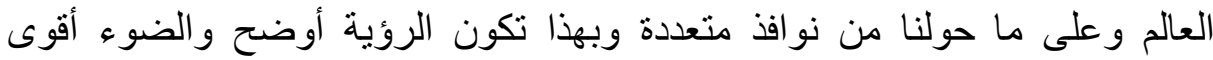
والآفاق أرحب.

\section{بصمة الترجمة في تظور الحضارات الإنسانية}

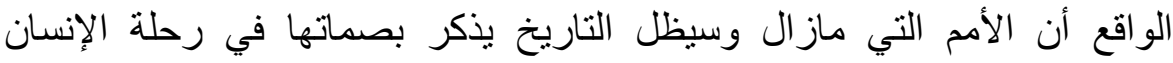

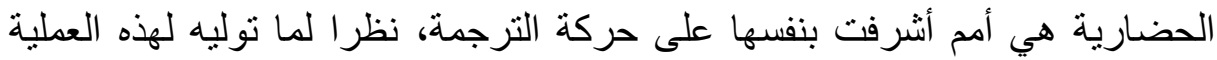

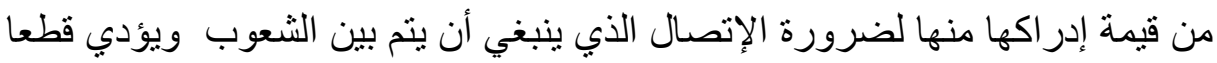

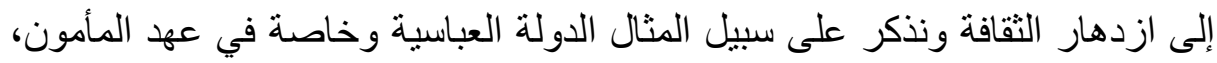

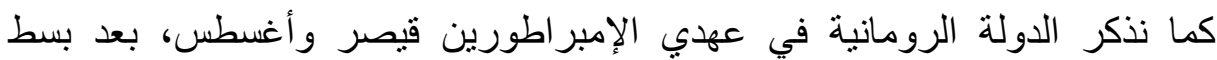

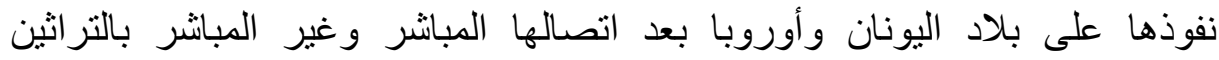

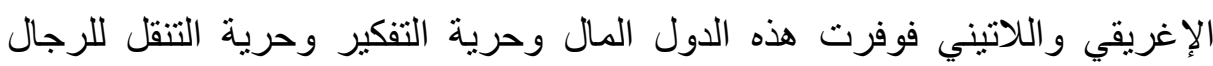

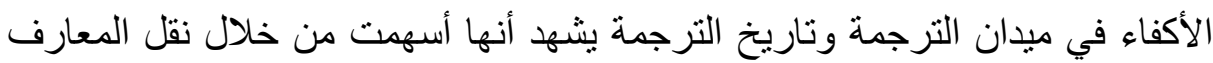

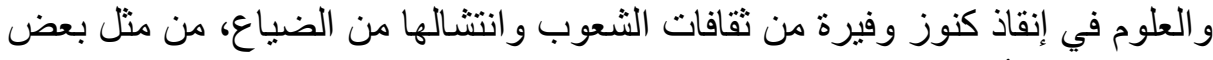

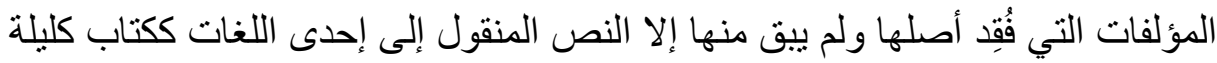

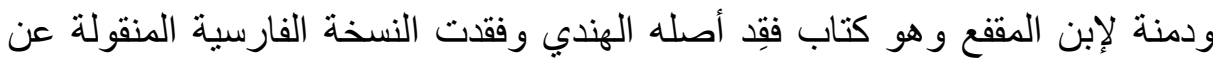

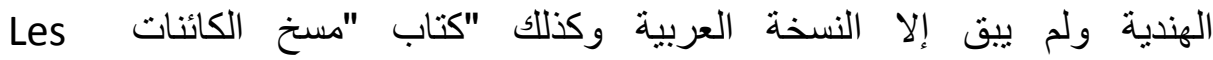
Métamorphoses

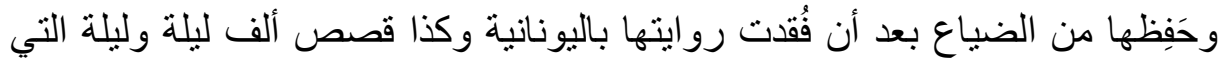
يعتقد الباحثون أن أصل جزء من حكاياتها إغريقي ولم يسبق منها الآن في التداول إلإنا

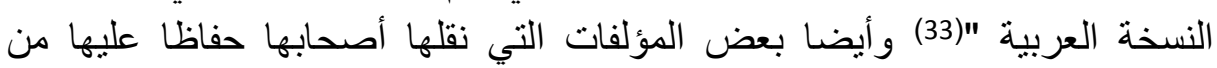

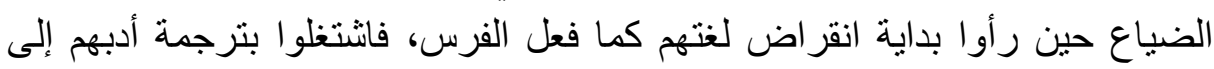

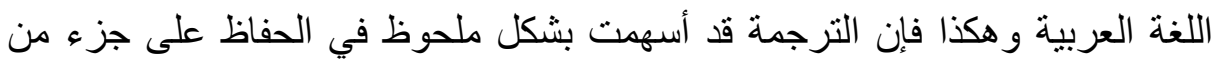

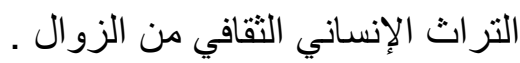

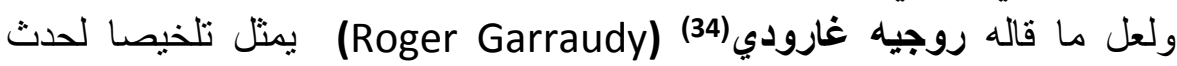

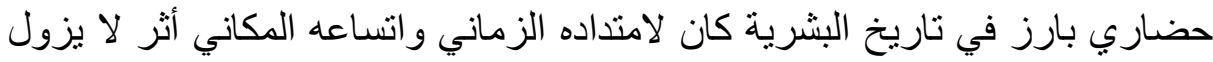

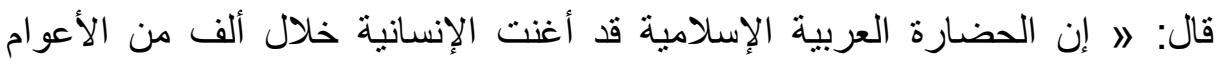

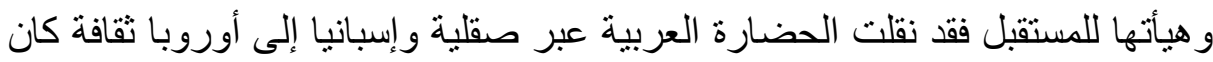

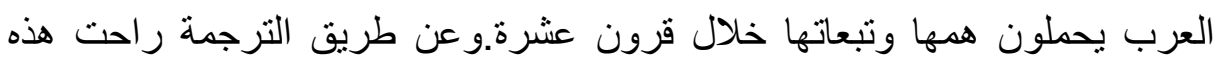

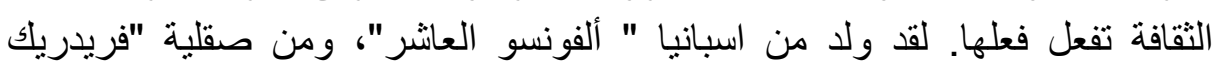


الثاني" وهما المعجبان بالحضارة العربية الإسلامية والمتحمسان لها، تلك الحضارة

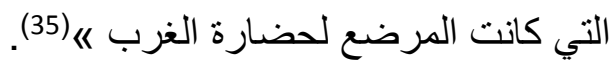

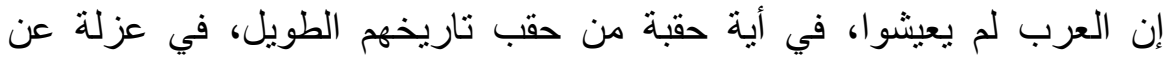
الثعوب الأخرى ولاسيما الثعوب المجاورة لهم، بل كانوا على اتصال معها،

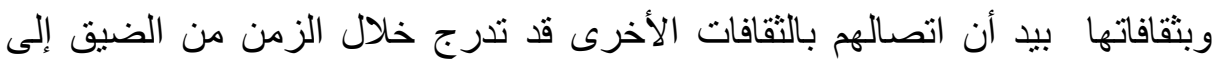
الاتساع ومن الضعف إلى القوة، ومن القلة إلى التنوع والكثرة ولهذا فإنه من

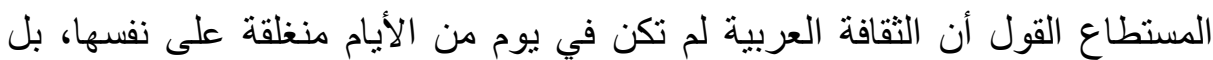

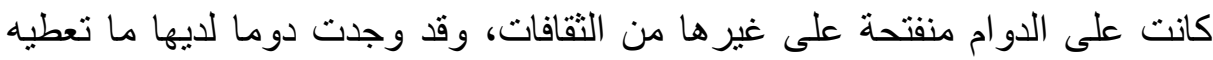
للآخرين كما لم تجد حرجا في اقتباس ما كانت بحاجة إليه. كذلك كانت على التى امتداد

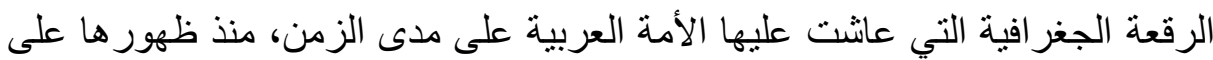
مسرح التاريخ. ومن أجل ذلك نقول إن الثقافة العربية كانت في الماضي تحمل سمة عالمية، لقد

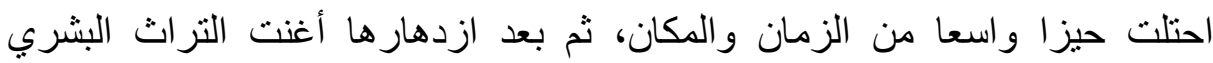

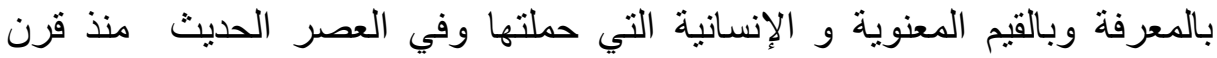

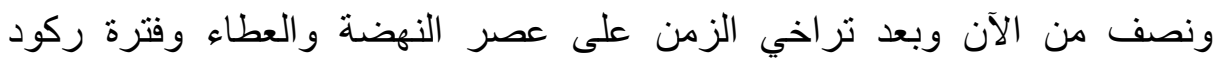

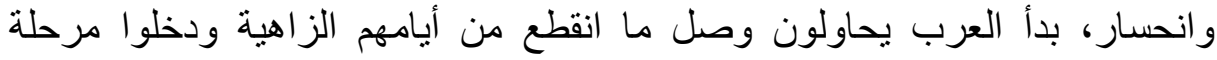
اليقظة القومية و الفكرية.

\section{دور الترجمة في إثراء الهوية الثقاية الثرية العربية}

كان للترجمة وسيكون دور فاعل بنّاء يحقق هدفين اثنين:

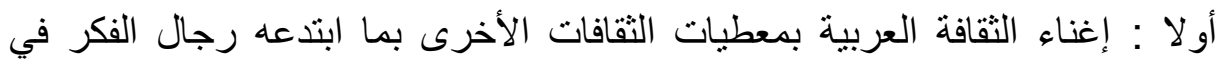

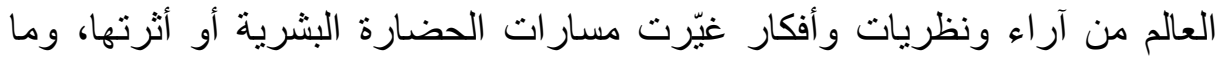

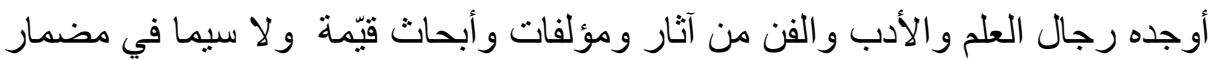

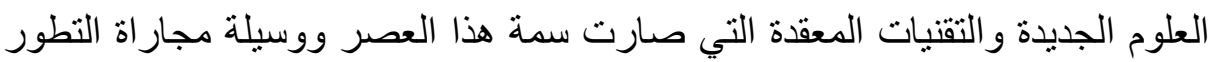

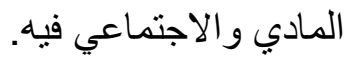

تانيا: تعريف الناطقين باللغات الأجنبية الرئيسية بروائع الفكر العربي قديمة وحديثة

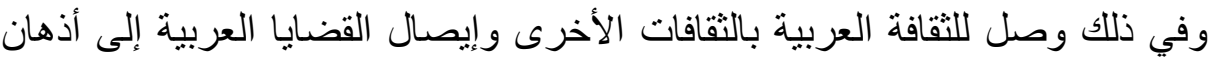
الآخرين وتشكيل صورة حقيقية للعربي في عقول أثرت فيها الدعايات المغرضة

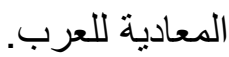

في هذا الأخذ والعطاء تأكبد للهوية العربية التقافية، إن الهوية الثقافية كيان مستقل

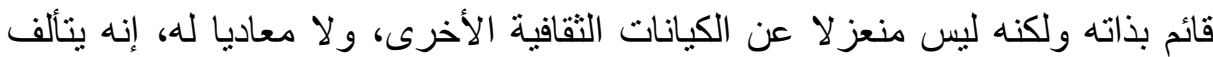

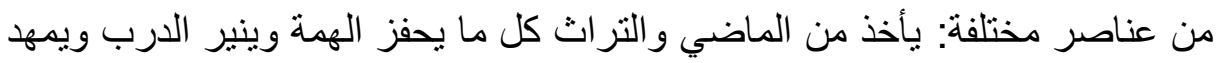

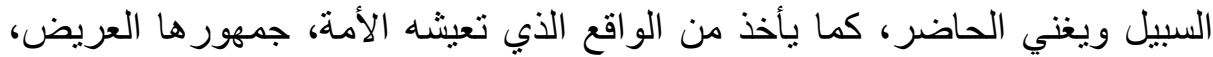

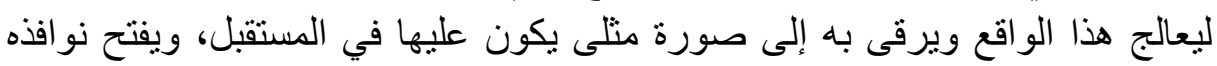

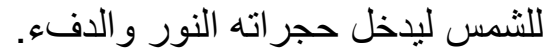

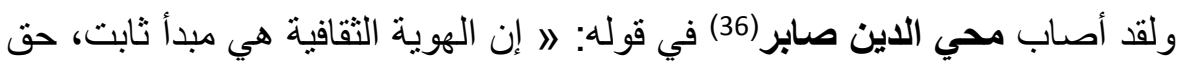

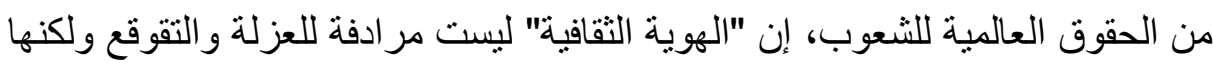

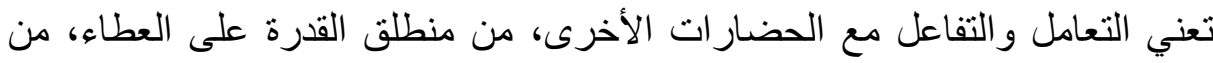

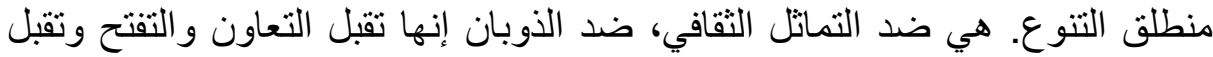
الأنماط الثقافية العالمية ولكنها في الوقت نفسه تدعو إلى تملك القدرة على الإسهام 
فيها، وذللك بتقوية مقوماتها الأساسية والحفاظ على قيمها باعتبار ها اختراعا إنسانيا

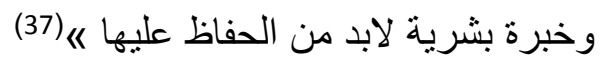

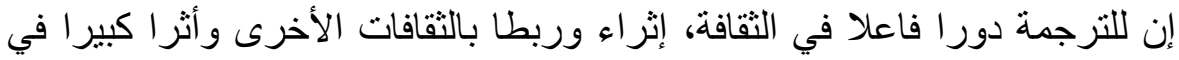

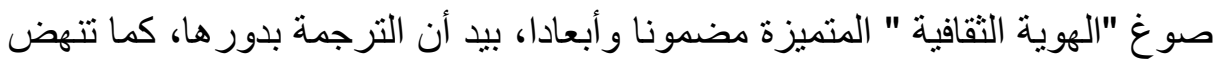

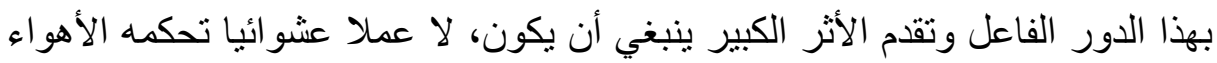

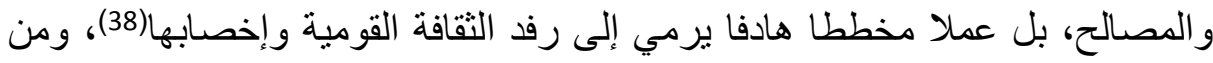

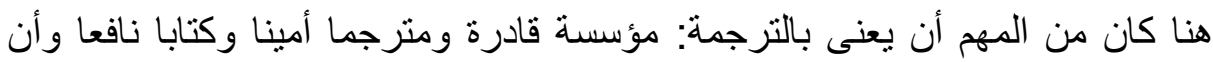

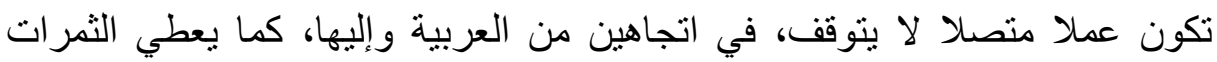

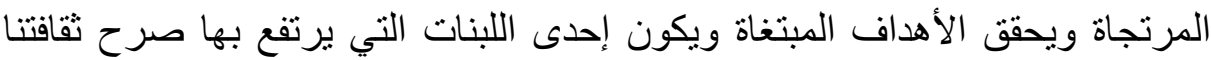

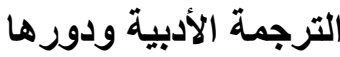

يقصد بالترجمة الأدبية ترجمة الآثار والمؤلفات الأدبية مثل الرواية والقصة

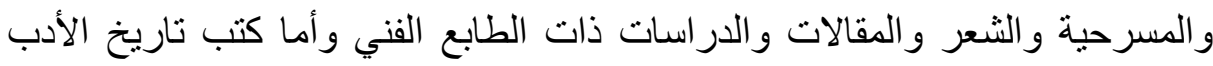

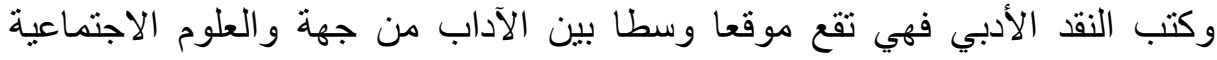

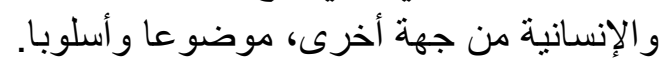

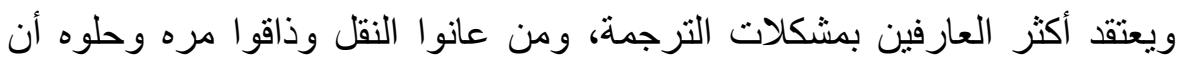

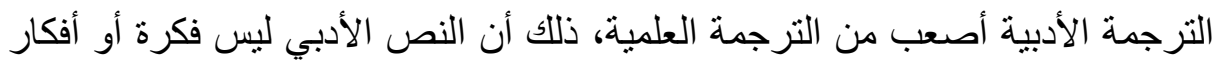

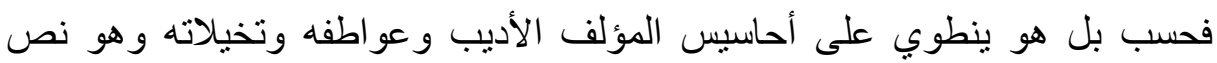

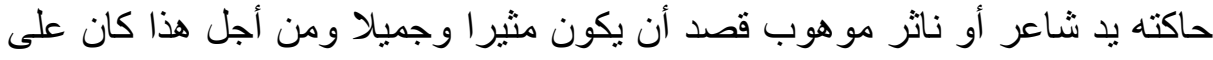

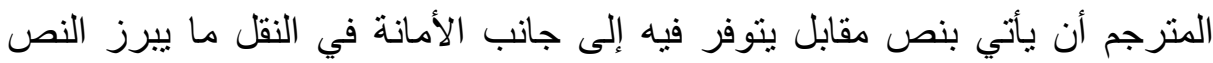
الأصلي و لا يضعف أثره و لا ينقص من بن جمالئ.

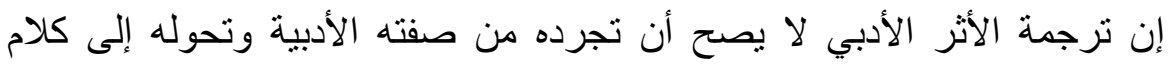

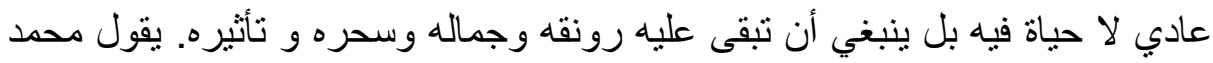

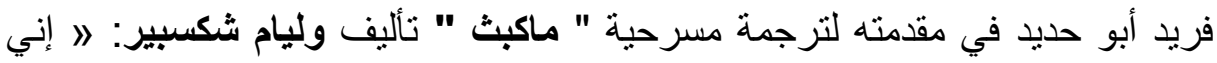

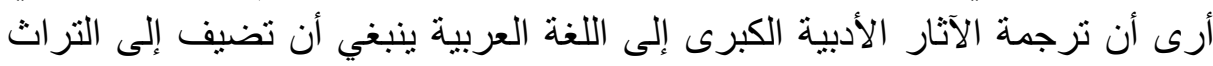

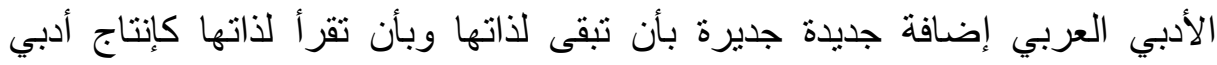

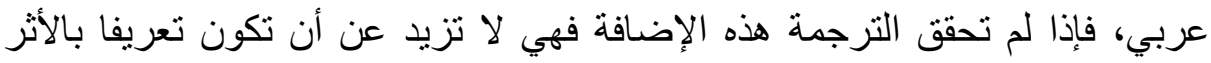

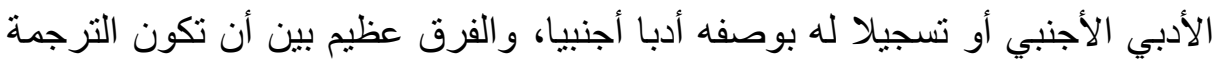

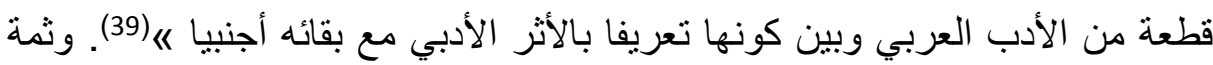

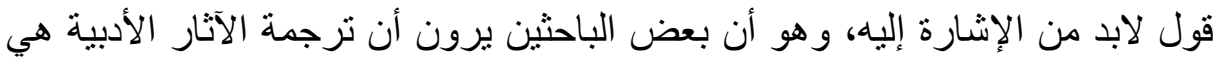

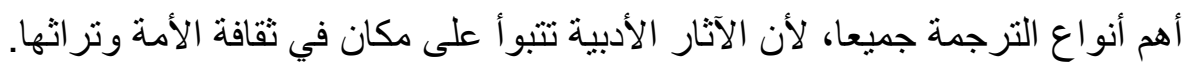

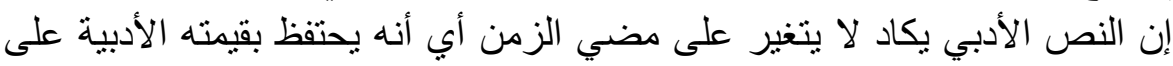

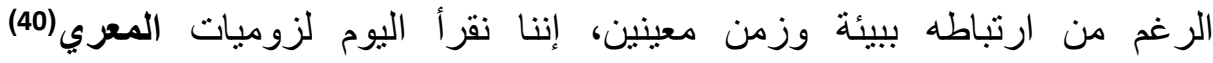

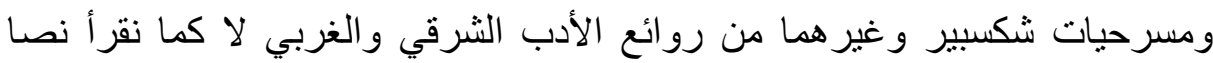

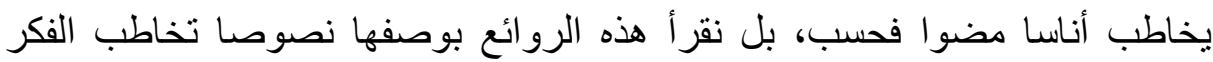

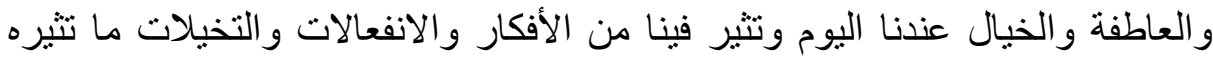

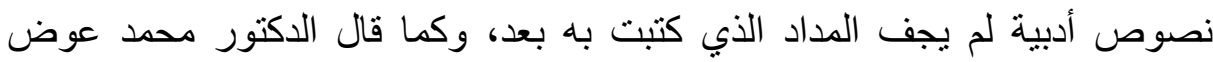


محمد: / الكلام الجميل ينبغي أن يقابله كلام جميل، وما يحسه من يقر أ الأصل يجب

أن يثابهه ما يحسه من بطالع الترجمة هـ (41).

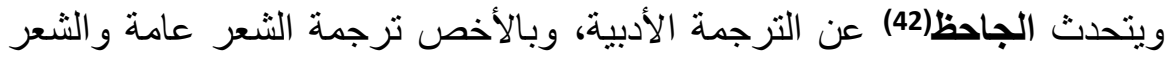

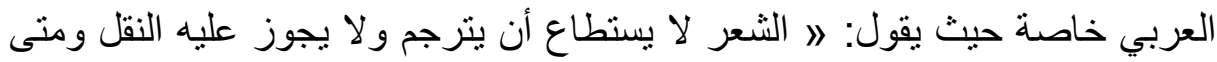

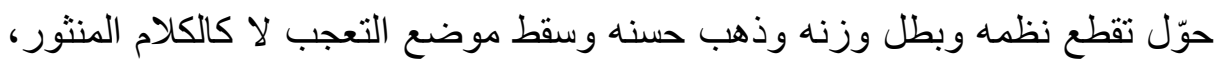

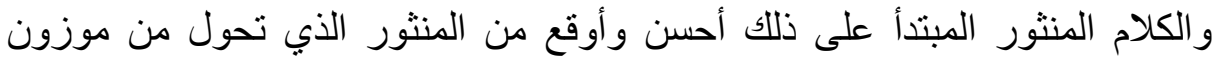

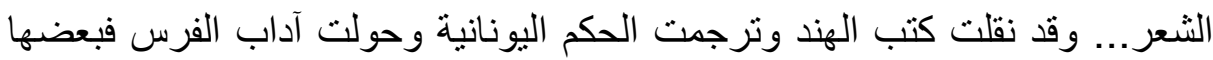

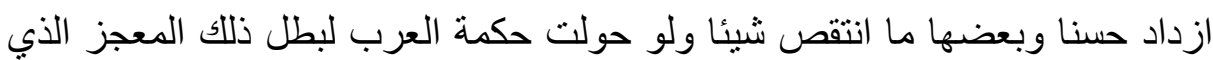

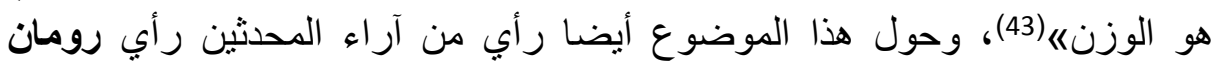

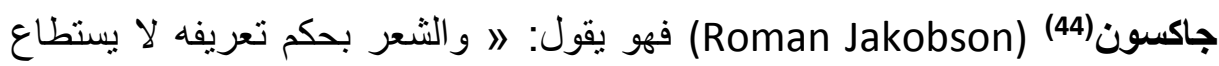

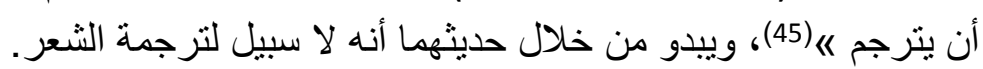

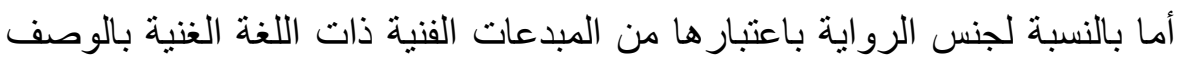

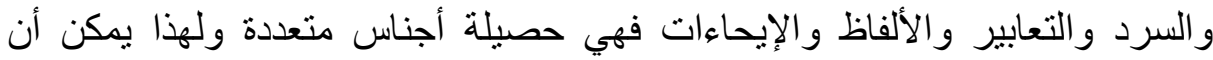

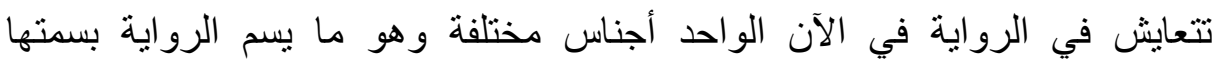

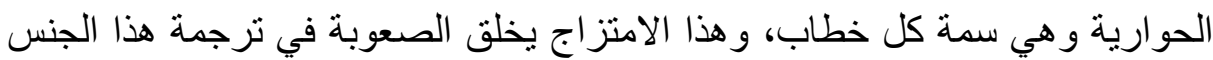

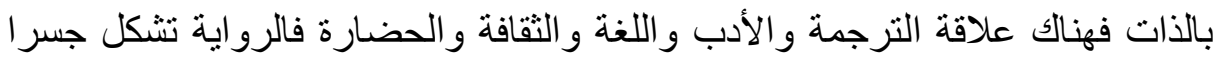

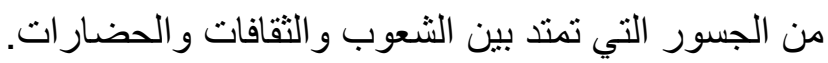

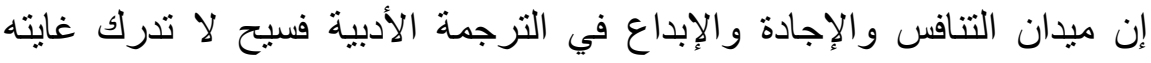

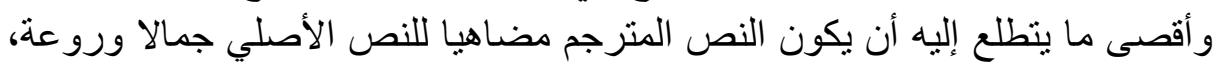

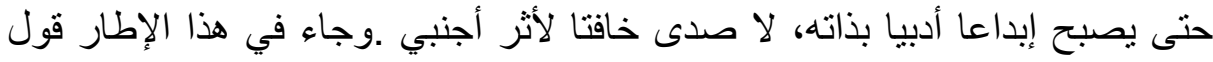

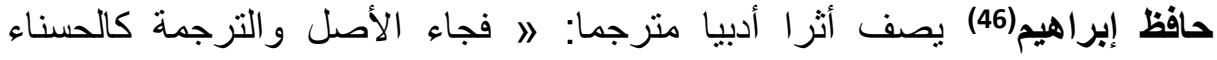

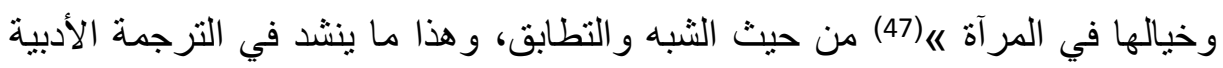

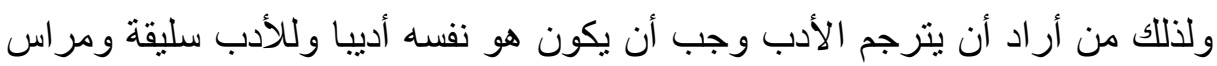

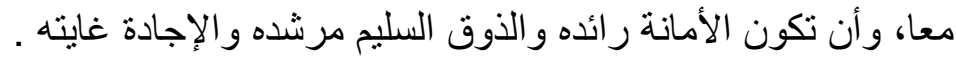

خاتمة

إن الترجمة عن اللغات تثري الهوية الثقافية وتقويها، ولا تضعفها أو تشوش

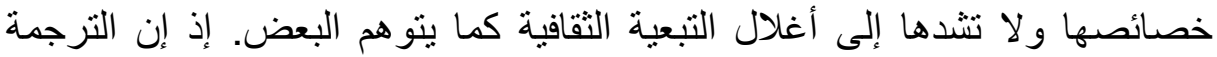

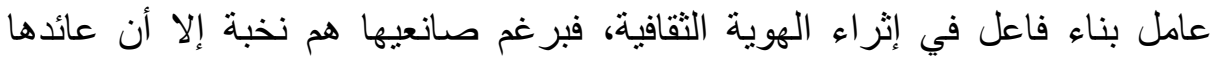

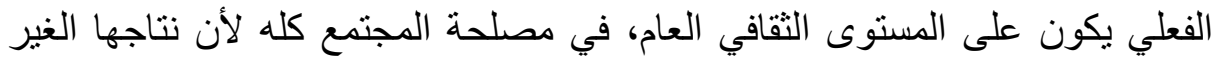

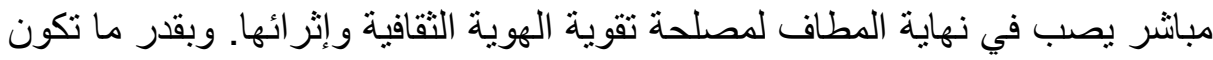

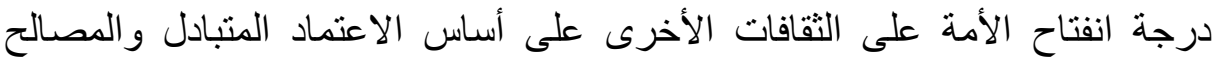
المشتركة، بقدر ما تتحدد وتيرة حركة الترجمة من اللغات الأخرى وسرعة الإنى إيقاعها؛

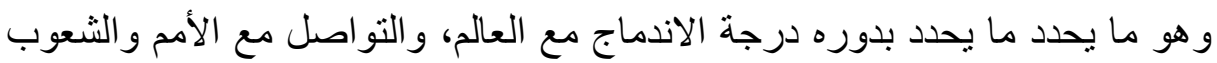

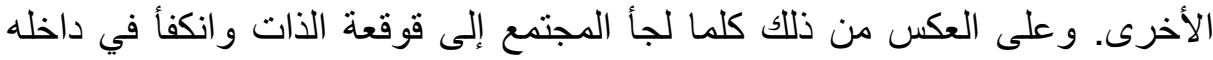

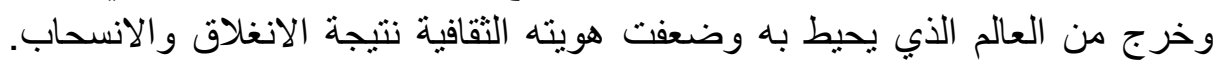

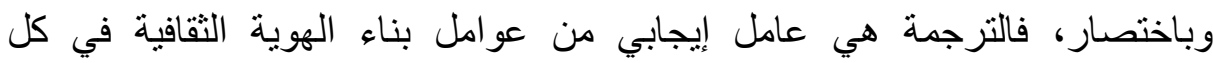


* إبر اهيم زكي خورشيد: الترجمة ومشكلاتها، الهيئة المصرية للكتاب، القاهرة، .1986

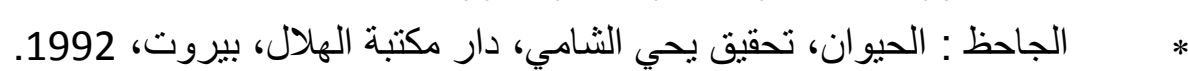

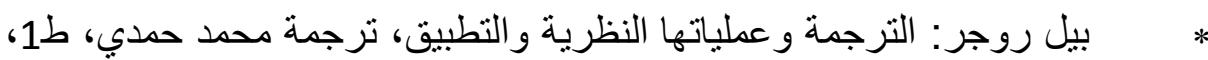
مكتبة العبيكان الرياض، 2001.

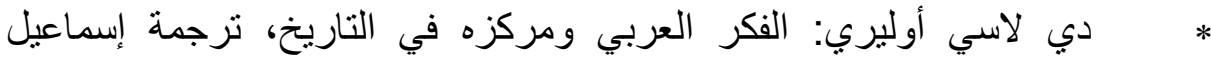

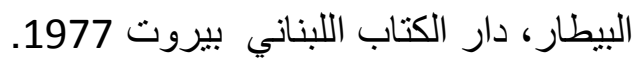

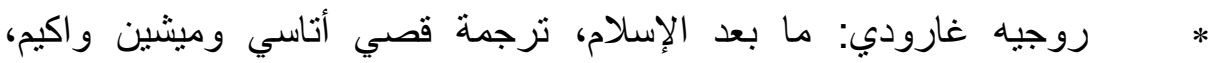
.1983

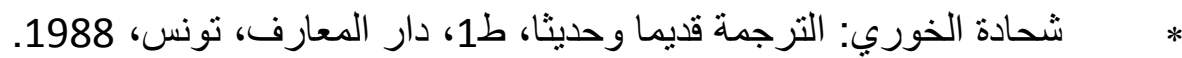

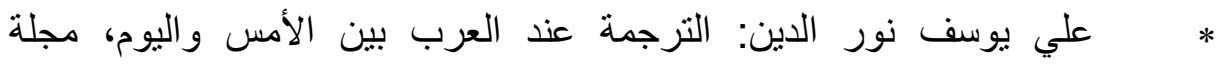
المترجم،04، دار الغرب، جوان 2002.

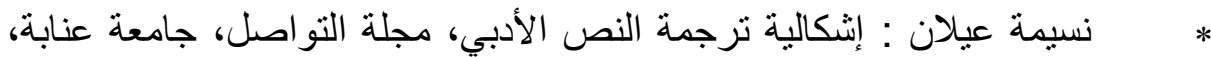
جوان 1999.

* محمد عوض محمد: فن الترجمة، معهد البحوث والدراسات العربية، جامعة

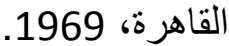

* محي الدين صابر: العلاقات بين اللغات الإفريقية والعربية، مجلة العربي،ع

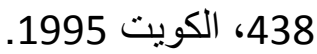

* منجية عرفة منسية: الترجمة عند العرب القدامى، الترجمة بين المعادلة و التطبيق، أشغال الندوة الدولية(ج3) منشورات المعهد العالي للغات، نونس، * BERMAN. Antoine, la traduction et la lettre ou l'auberge du lointain. Seuil. Paris. 1999.

* DEPRE OSEKI. Inès, Théorie et pratiques de la traduction littéraires. Armand Collin. Paris. 1999. P. 101.

* DE WOARD .J et NIDA.E, D'une langue à une autre. Alliance biblique universelle. Villhers-le-bel-France. 2003. Préface.

* YAKOBSON. Roman: Essais de linguistique générale Trad .Rewet, N.ed Minuit, Paris, 1963. 
(1)- شحادة الخوري: الترجمة حديثا وقديما، ط1، دار المعارف، ، تونس، 1988،

(2)- ينظر : ابن منظور : لسان العرب، دار صادر ، بيروت، 1994.

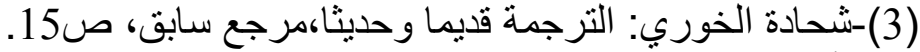

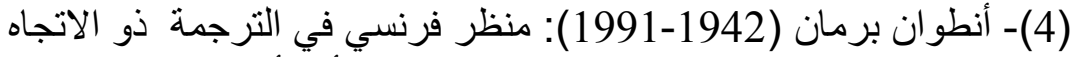

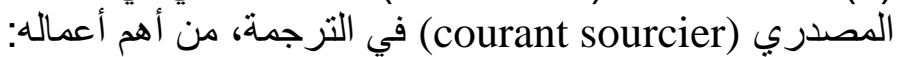

L'épreuve de l'étranger (1984).

(5)-BERMAN. Antoine, la traduction et la lettre ou l'auberge du lointain. Seuil. Paris. 1999. P. 25.

(6)-و التر بنيمين (1892-1940): كاتب وناقد ومنظر ألماني في الترجمة ذو الاتجاه المصدري ، ترجم لبلز الك وبودليير.

(7)-DEPRE OSEKI. Inès, Théorie et pratiques de la traduction littéraires. Armand Collin. Paris. 1999. P. 101.

(8)-DEPRE OSEKI. Inès, Théorie et pratiques de la traduction littéraires. Armand Collin. Paris. 1999. P. 106.

(9)-بيل روجر : أستاذ ودكتور بمدرسة اللغات بمعهة وسط لندن التقني.

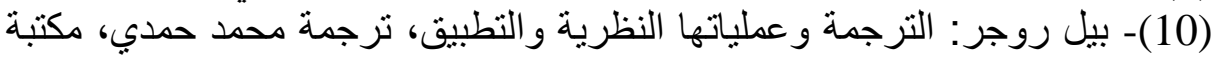

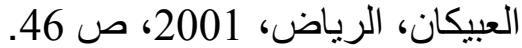

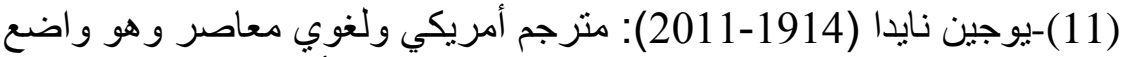

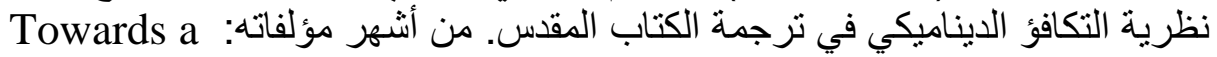
Science of Translating (1964)

(12)-جان دي وارد (1931-2016): كاتب وأستاذ نرجمة بجامعة أمستردام، مستشار الترجمة في "Alliance biblique universelle" من أهم كتبه: From one language to anther. Functional equivalence in Bible بالتنسيق مع يوجين نايدا. Translating

(13)-DE WOARD .J et NIDA.E, D'une langue à une autre. Alliance biblique universelle. Villhers-le-bel-France. 2003. préface du livre.

(14)- وليام شكسبير (1564-1616): شاعر وكاتب مسرحي وممثل انجليزي، سمي (1603)

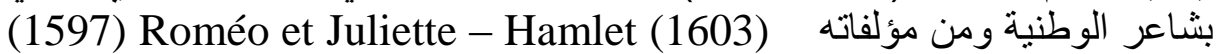

- Othello (1604) - Macbeth (1623)

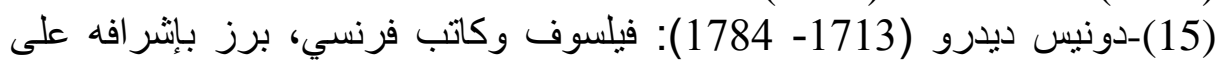
إصدار "موسوعة الفنون والعلوم و الحرف" ومن ون قادة حركة "التنوير". رئيس تحرير

أول موسوعة Encyclopédie.

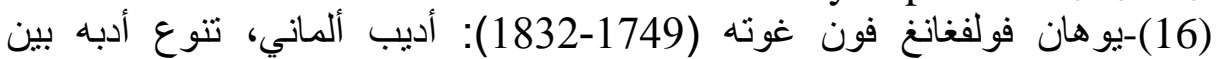

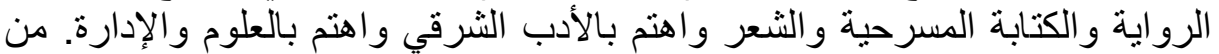

مؤلفاته:1773 Le neveu de Rameau (1762-173) (17)-أنطوان غالان (17646-1715): مستشرق فرنسي، أنتتهر بترجمة ألف ليلة

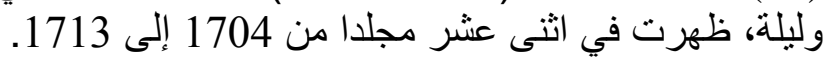

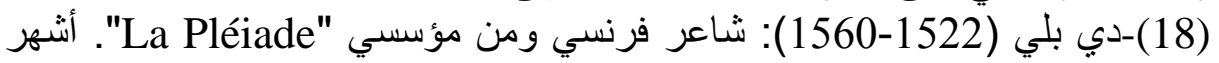

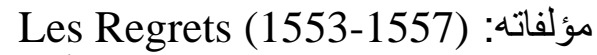
(19)-مارتن لوثر (1483-1546): أستاذ جامعي، من مصلحي الكنيسة البروتستانتية ومغيري مسار الحضارة الغربية. 
(20)- فر انشيسكو بتراركا أو بتر ارك (1304 -1374): باحث و شاعر إيطالي وأحد

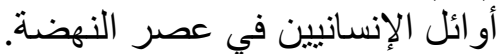

(21)- نسيمة عيلان: إثكالية نرجمة النص الأدبي، مجلة التواصل، جامعة عنابة،

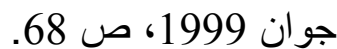

(22)-ينظر: منجية عرفة منسية: الترجمة عند العرب القدامى، الترجمة بين المعادلة

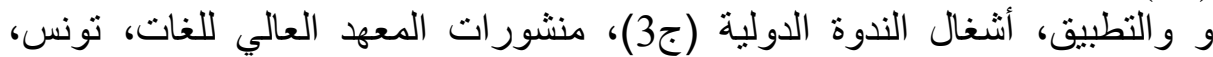

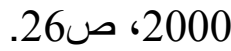
(23)-ينظر: إبر اهيم زكي خورشيد: الترجمة ومشكلاتها، الهيئة المصرية للكتاب،

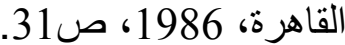

(24)- ينظر: علي يوسف نور الدين: الترجمة عند العرب بين الأمس واليوم، مجلة

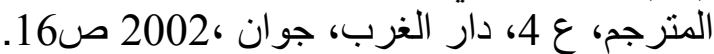

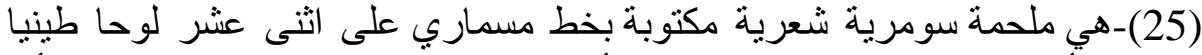

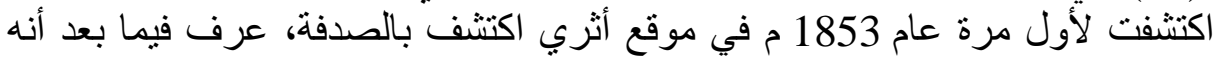

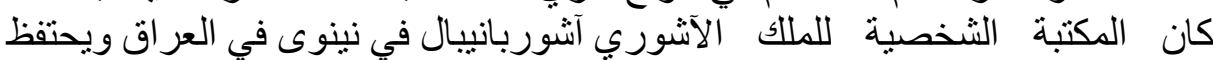

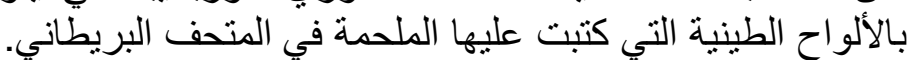

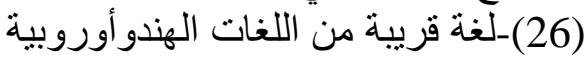

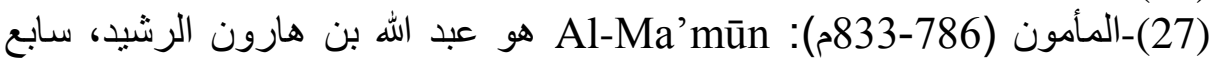

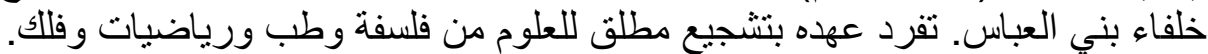
(28)-دي لاسي أوليري: الفكر العربي ومركزه في التاريخ، ترجمة إسماعيل البيطار، ولئه

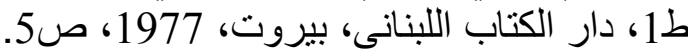

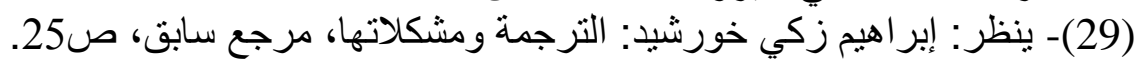

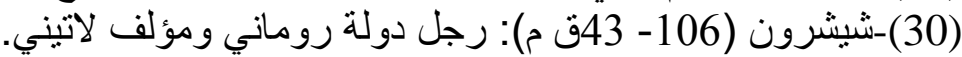

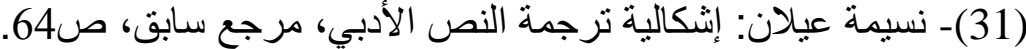
(32)- أوفيد (43-183 م): شاعر لاتيني شهد ولادة الإمبر اطورية الرومانية، أشهر

مؤلفاته: L'Art d'aimer \& Les Métamorphoses

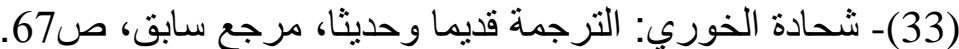

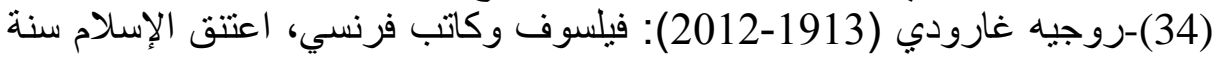

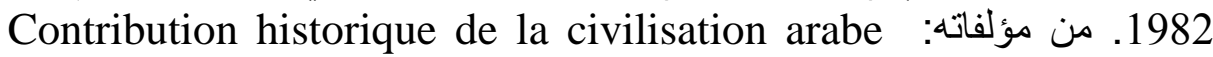
(1946) et Mosquée, miroir de l'Islam

(35)-روجيه غارودي : ما بعد الاسلام، ترجمة قصي أتاسي وميشين و اكيم، 1983، ص140.

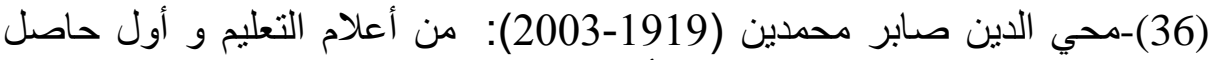

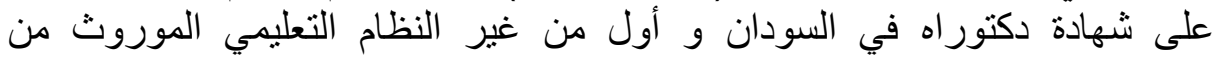

(37)-محي الدين صابر: العلاقات بين اللغات الإفريقية والعربية، مجلة العربي،

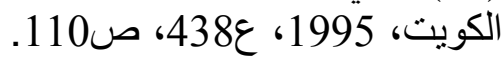
(38)-محي الدين صابر : العلاقات بين اللغات الإفريقية و العربية، نفس المرجع.

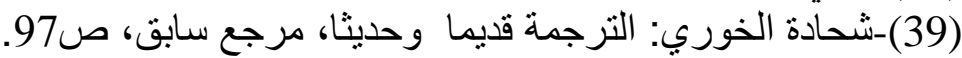

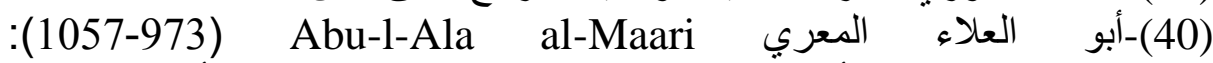
شاعر وفيلسوف ولغوي وأديب عربي من عصر الدولة العباسية. من أثنهر مؤلفاته:

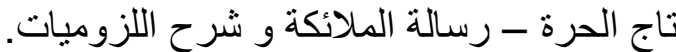

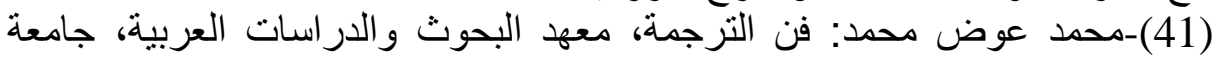

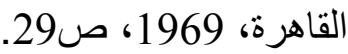


(42)- الجاحظ Al-Jahiz (

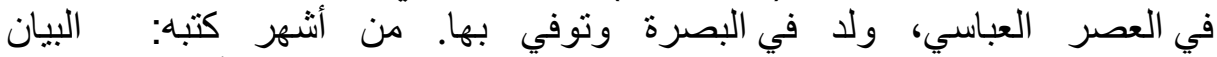

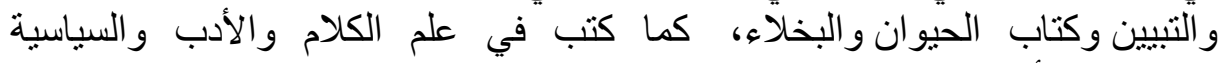

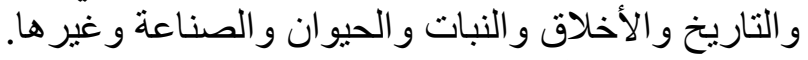

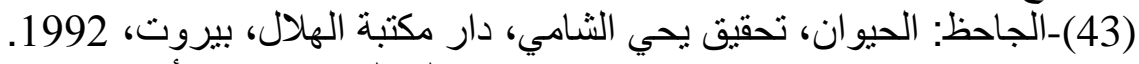

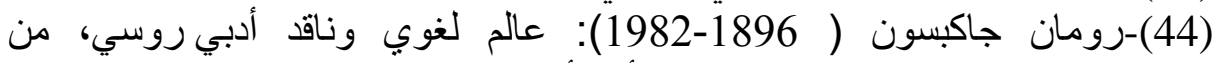

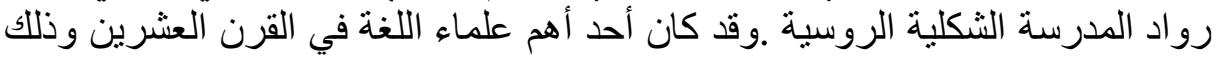

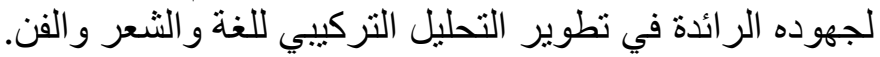
(45)- YAKOBSON.R, Essai de linguistique générale, Trad. Rewet, N. ed Minuit, Paris, 1963, p. 45.

(46)- حافظ إبراهيم Hafez Ibrahim (1932-1972): شاعر مصري ذائع الصيث. عاصر أحمد شوقي ولقب بشاعر النيل وبشاعر الشعب. من مؤلفاته: الديوان.

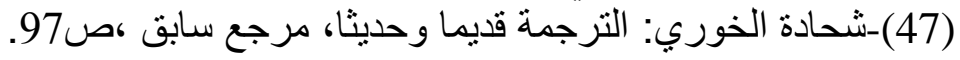

